\title{
Are Pain Intensity and Pain Related Fear Related to Functional Capacity Evaluation Performances of Patients with Chronic Low Back Pain?
}

\author{
Michiel F. Reneman • Henrica R. Schiphorts Preuper • \\ Marco Kleen • Jan H. B. Geertzen • Pieter U. Dijkstra
}

Published online: 13 March 2007

(C) Springer Science + Business Media, LLC 2007

\begin{abstract}
Introduction: Pain related fear and pain intensity have been identified as factors negatively influencing Functional Capacity Evaluation (FCE) performances in patients with CLBP. Conflicting results have been reported in the literature. The objective of this study was to analyze the relationships between pain intensity and pain-related fear on the one hand, and performances during an FCE on the other hand in two samples of patients with chronic low back pain (CLBP). Methods: Two cross sectional observation studies were performed with two samples of patients with CLBP (study 1: $n=79$; study 2: $n=58$ ). Pain related fears were operationally defined as the score on the Tampa Scale of Kinesiophobia in study 1, and the Fear Avoidance Beliefs Questionnaire (FABQ) in study 2. Pain intensity was measured with a Numeric Rating Scale in both studies. Avoidance behavior observed during FCE was in both studies operationally defined as the unwillingness to engage in high intensity performance levels of three different functional activities: high intensity lifting, prolonged standing in a forward bend position, and fast repetitive bending at the waist. Results: A total of 25 correlations between pain and pain related fear, and performance variables were calculated, out of which 7 were significant $(p<0.05)$. The strength of these significant correlations ranged from $r=-0.23$ to $r=-0.50$. Multivariate linear regression analyses revealed non-significant relationships in most instances. Pain and pain related fear contributed little if any to these models. Conclusions:
\end{abstract}

M. F. Reneman $(\bowtie) \cdot$ H. R. Schiphorts Preuper · M. Kleen · J. H. B. Geertzen · P. U. Dijkstra Center for Rehabilitation, University Medical Center Groningen, University of Groningen, P.O. Box 30.002, 9750 RA, Haren, The Netherlands

e-mail: m.reneman@cvr.umcg.nl

M. F. Reneman

Center for Occupational Health, University Medical Center Groningen, University of Groningen, The Netherlands

M. F. Reneman · J. H. B. Geertzen · P. U. Dijkstra

Northern Center for Health Care Research, University of Groningen, University of Groningen,

The Netherlands

P. U. Dijkstra

Department of Oral and Maxillofacial Surgery, University Medical Center Groningen,

University of Groningen, The Netherlands 
The relation between pain and pain related fear and FCE performance is weak or non-existent in patients with CLBP.

Keywords Pain cognitions · Disability Assessment $\cdot$ Rehabilitation $\cdot$ Lifting - Tampa scale for Kinesiophobia · Fear Avoidance Beliefs Questionnaire

\section{Introduction}

Functional Capacity Evaluations (FCEs) are batteries of tests designed to assess a person's functional capacity related to work [1-3]. To establish functional capacity, the patient is asked to perform a number of activities. Combined, these performances reflect a patient's ability to perform work-related activities. A patient's performance is determined by biological, psychological and social factors [4]. Pain related fear, also referred to as fear avoidance beliefs or fear of movement and reinjury [5], and pain [6] have been identified as examples of psychological factors influencing a patient's performance during an FCE.

Pain related fear refers to a condition in which the patient has an excessive, irrational, and debilitating fear of physical movement and activity, resulting in feelings of vulnerability to painful injury or reinjury $[7,8]$. People who experience pain-related fear will avoid activities they associate with increased risk for pain or (re)injury. As such, pain-related fear should have a negative effect on the results of performance testing [5, 9]. It has been stated that 'a valid assessment of functional capacity cannot be carried out without controlling for fear avoidance beliefs' [8]. Several studies were performed to study the relationship between pain-related fear and different types of avoidance behavior in patients with chronic non-specific low back pain (CLBP). The strength of this relationship varied between the studies from $r=0.06$ to $r=0.49$ $[8-10,11]$. The relationship between pain related fear and performance appeared stronger in studies where patients were observed under strictly controlled conditions $[8,10]$, and weaker in studies where patients were observed in a less controlled environment [11]. In a previous study performed in an admission phase for a pain rehabilitation program, no relationship was found in a sample of patients with CLBP, between lifting performance and pain-related fear [12]. Although the evidence from other studies did not overwhelmingly support the strength of the relationship, our results, presented in the Journal of Occupational Rehabilitation in 2003, were in contrast with other studies. It could not be determined whether the results found were weaker because of the operational definitions of pain-related fear (score on Tampa Scale for Kinesiophobia (TSK)) or avoidance behavior (maximum lifting performance). It was recommended that future studies should use additional operational definitions for pain-related fear and avoidance behaviors.

In a recent review pain intensity has been identified to consistently associate negatively with patient performances during FCEs [6]. The strength of the significant associations between pain intensity and FCE performances in patients with chronic pain vary from $r=-0.25$ to $r=-0.56$ [6]. In the study mentioned above, the relation between pain intensity and lifting performance was (somewhat) weaker and non-significant $(r=-0.21)$ [12].

Aim of this study was to further analyze the relationships between pain intensity and painrelated fear on the one hand, and avoidance behaviors on the other hand. Two studies were performed with separate samples of patients with CLBP. Pain related fears were operationally defined as the score on the TSK in study 1, and the Fear Avoidance Beliefs Questionnaire (FABQ) in study 2 . Avoidance behavior was in both studies operationally defined as the unwillingness to engage in high intensity performance levels of three different FCE tests: high intensity lifting, prolonged standing in a forward bend position, and fast repetitive bending at the waist. Nonsignificant or weak relationships were considered falsifications of the hypotheses that pain and Springer 
pain-related fears would have clinically relevant impact on FCE performances in patients with CLBP.

\section{Materials and methods}

Patients

Two separate cohorts of patients who were referred to an outpatient rehabilitation program of the Center for Rehabilitation of the Groningen University Medical Center, The Netherlands, were included. Both study samples consisted of patients diagnosed with CLBP, aged between 18 and 60 years, with symptoms lasting longer than 3 months. Excluded were patients with comorbidity with negative consequences for functioning (i.e. severe depression needing a psychiatric referral), and patients with specific pathology related to the lumbar spine (i.e. disc herniations, tumors, spondylolisthesis grade 3 or 4, etc.). Patients were not selected based on (high or low) levels of pain or pain related fears. Selection process of both study samples were equal, with the exception that patients in study sample 1 explicitly agreed to participate in a larger study in addition to regular clinical care [13]. The patients of sample 2 received regular clinical care only.

Procedures

Prior to the medical intake patients filled out a TSK [7, 8], a numeric rating scale to assess pain intensity (NRS), a Roland Morris Disability Questionnaire [14] (RMDQ) to assess disability, and a study consent form. The patients underwent the FCE approximately 2 weeks after the medical intake. Prior to the FCE, all patients were asked whether their pain and functional status was different compared to their status during medical intake. In study 2, patients filled out the FABQ [15] prior to the FCE. For study 1, approval was granted by the medical ethics committee of the University Medical Center Groningen, The Netherlands. The data of the patients of study sample 2 were collected as part of regular clinical procedures, for which institutional approval was received.

Measures

Patients rated their current pain intensity on a NRS ranging from 0 to $10 ; 0$ being no pain at all and 10 being the worst pain imaginable. Self reported disability was assessed by the RMDQ [14]. Scores on the RMDQ can range from 0 to 24; 0 indicating no disability and 24 indicating severe disability. The psychometric properties of the RMDQ are good $[14,16]$.

Pain related fear was assessed with a different questionnaire for each sample. In study 1, pain related fear, called fear of movement and reinjury, was assessed by the TSK [8]. The TSK consists of 17 items. Each item is provided with a 4-point Likert scale with scoring alternatives ranging from "strongly disagree" to "strongly agree." Although the scale consists of 2 subscales, activity avoidance and somatic focus, a total score is usually presented. The total score ranges from 17 to 68. The reliability of the TSK is fair [8]. Criterion validity was established from correlations with other self-reported measures of fear (of bodily injury), anxiety, depression, and catastrophizing [8].

In study 2, pain related fear, called fear avoidance beliefs, was assessed by the FABQ [10, 15]. The FABQ consists of 16 items. Each item is provided with a 7-point Likert scale with scoring alternatives ranging from 0 to 6 . The FABQ consists of 2 scales. The activity scale consists of 4 items (total score 0-24), the work scale consists of 6 items (total score 0-36). The remaining 4 items are not used. The reliability of the FABQ is good in patients with acute and subacute back pain [17], but has not been established in patients with CLBP. 
Avoidance behavior was assessed during an FCE. The patients were asked to perform 14 different activities to their maximum abilities ( 3 types of lifting, carrying, pushing, pulling, overhead work, stooping, crouching, kneeling, standing, walking, sitting, stair climbing), according to the protocols of Isernhagen Work Systems [18]. Selection of activities was based on the Dictionary of Occupational Titles (DOT), thus assuming construct validity with regard to work [19]. Three activities tested during the FCE were selected for this study, because they might be potentially harmful for patients with CLBP [20]. These activities were lifting, static bending and dynamic bending. Lifting was assessed by means of a standardized lifting task consisting of lifting a receptacle with incremental weights from a table $(74 \mathrm{~cm})$ to the floor and vice versa. 'Ergonomically correct' body mechanics were not emphasized [21]. The patient's maximum was reached in four to five increments. The maximal amount lifted five times within 90 seconds was recorded (kilograms). Test-retest reliability of the lifting task is good in patients with CLBP [22-24]. During lifting, heart rate was measured using a heart rate monitor. In study 2, the intensity level of lifting was observed by the evaluator, and recorded by means of a Borg CR-10 scale. The reliability and validity of this procedure is good [25]. These observations were not recorded in study 1 . During the static bending capacity test the patient was asked to stand as long as possible with his / her trunk $30-60^{\circ}$ flexed forward, while performing a simple manipulation task. The time this position was held was recorded (seconds). Test-retest reliability of this test in patients with CLBP is good [22]. For the dynamic bending test, the patient is asked to bend at the hips and back as fast as possible, pick up a small object from the floor, and to remove this object to a shelf at crown level (top of head). This was repeated 20 times. The number of repetitions completed and the time needed to complete this activity was recorded (seconds). Test retest reliability of this test in patients with CLBP is moderate to good [22]. The construct validity of the tests has been established [26, 27]. Before testing, patients were instructed regarding termination of the test. Testing was terminated when one of the following occurred: the patient stated verbally that he/she wished to terminate the activity, the heart rate reached $85 \%$ of the age-related maximum, indicated by a heart rate monitor, or the evaluator deemed further testing to be unsafe. No verbal reassurance was given during the testing procedures. The evaluator was blinded to the questionnaire scores.

\section{Analysis}

Descriptive statistics were used to describe the study samples. All variables of interest were analyzed at interval level. A student t-test was used to analyze differences between males and females. When differences were significant, further analyses were performed separately for males and females. Pearson product moment correlations were calculated to express linear associations between pain intensity and measures of pain related fear on the one hand and performance variables on the other hand. Correlations were interpreted as follows: 0.25 or less little if any relationship, $0.26-0.49$ poor relationship, $0.50-0.69$ moderate relationship, 0.70 0.89 strong relationship, $0.90-1.00$ very strong relationship [28]. Pain intensity and pain related fear, as well as gender, age and self-reported disability were entered as predictor variables in a multivariate linear regression model (method: enter) and performances as outcome variables. A p-value of $<0.05$ was considered statistically significant for all analyses.

\section{Results}

The characteristics of the patients participating in study 1 and 2 are presented in Table 1. All patients declared that their pain and functional status had not changed between medical intake Springer 
Table 1 Age, pain intensity, self-reported disability, pain related fear (TSK or FABQ), and performance variables of 2 samples of patients with chronic low back pain

\begin{tabular}{|c|c|c|c|c|}
\hline & \multicolumn{2}{|l|}{ Study $1(n=79)$} & \multicolumn{2}{|l|}{ Study $2(n=58)$} \\
\hline & $\begin{array}{l}\text { Males }(n=49) \\
\text { Mean }(\mathrm{SD})\end{array}$ & $\begin{array}{l}\text { Females }(n=30) \\
\text { Mean }(\mathrm{SD})\end{array}$ & $\begin{array}{l}\text { Males }(n=39) \\
\text { Mean }(\mathrm{SD})\end{array}$ & $\begin{array}{l}\text { Females }(n=19) \\
\text { Mean }(\mathrm{SD})\end{array}$ \\
\hline Age (years) & $37.8(9.0)$ & $37.8(8.8)$ & $40.4(8.6)$ & $35.6(8.3)$ \\
\hline Pain intensity (NRS; 0-10) & $4.7(2.3)$ & $5.0(1.6)$ & $4.5(2.4)$ & $4.9(2.2)$ \\
\hline $\begin{array}{l}\text { Self-reported disability } \\
\text { (RMDQ; 0-24) }\end{array}$ & $12.5(4.4)$ & $12.4(4.7)$ & $11.6(4.4)$ & $11.2(5.9)$ \\
\hline TSK (17-68) & $37.5(5.3)$ & $36.0(5.6)$ & N/A & N/A \\
\hline FABQ activity scale (0-24) & N/A & N/A & $13.4(4.1)$ & $13.2(5.6)$ \\
\hline FABQ work scale $(0-36)$ & N/A & N/A & $19.3(9.5)$ & $15.1(11.6)$ \\
\hline Lifting performance $(\mathrm{kg})^{*}$ & $31.7(14.7)$ & $18.9(8.1)$ & $32.3(3.8)$ & $20.5(6.3)$ \\
\hline $\begin{array}{l}\text { Lifting maximum heart rate } \\
\text { (BPM) }\end{array}$ & $126.7(15.8)$ & $129.7(23.5)$ & $128.2(14.5)$ & $128.8(19.3)$ \\
\hline Static forward bend (sec) & $187.4(148.9)$ & $230.6(146.3)$ & $188.0(115.8)$ & $237.3(154.8)$ \\
\hline $\begin{array}{l}\text { Dynamic forward bend } \\
\text { (sec/rep) }\end{array}$ & $2.8(0.7)$ & $3.2(1.3)$ & $3.2(1.6)$ & $2.9(0.8)$ \\
\hline
\end{tabular}

SD: standard deviation; NRS: Numeric Rating Scale; RMDQ: Roland Morris Disability Questionnaire; TSK: Tampa Scale for Kinesiophobia; FABQ: Fear Avoidance Beliefs Questionnaire; BPM: beats per minute; N/A: not assessed. *: Difference between males and females significant in both studies $(p<0.05)$.

Note. Differences between the study samples were non-significant $(p<0.05)$.

and the FCE. Scores on the TSK subscale in study 1 are: activity avoidance males mean 19.1 (SD 3.8), females mean 18.9 (3.3); somatic focus males mean 9.7 (2.5), females mean 9.2 (2.6). The 20 repetitions of the dynamic bending test were not completed by 10 (of $79,13 \%$ ) patients in study 1 and by 6 (of 58,10\%) patients in study 2. To correct for differences in number of repetitions, the time needed to complete one repetition was calculated and presented (time/number of repetitions). The observed level of intensity of the maximal lifting performances in study 2 were for males mean 7.2 (SD 2.2) and for females 7.4 (SD 1.6) (Borg CR-10 scale). Observational data was unavailable in study 1 . Within the study samples, differences between males and females were non-significant, with the exception of the maximum lifting performance. Between the study samples, none of the differences were significant.

A total of 25 correlations between pain intensity, TSK (study 1) and FABQ (study 2) and performance variables are presented in Table 2 . The strengths of the correlations were moderate in one occasion and otherwise weak/poor or non-significant. Pain intensity explained $25 \%$ of the variance of the performances of male lifting performance in study $2(r=-0.50)$. In all other analyses over both studies, the explained variance between pain intensity and performance variables was $8 \%(r=-0.29)$ or less. The FABQ work scale explained at best $13 \%$ of the variance of the performances (male lifting performance in study $2 ; r=-0.37$ ). The correlation between either TSK subscales with any of the performance variables was non-significant. No differences were observed between patients who did or did not complete 20 repetitions of the dynamic bending test concerning their relationship with the TSK or the FABQ (all nonsignificant). The correlation between observed intensity of lifting and FABQ work scale was $\mathrm{r}=-0.27$ (significant). The correlation between observed lifting intensity and FABQ activity scale was $r=-0.07$ (not significant).

Analyses were performed on the subgroups of patients scoring in the highest quartile of the pain intensity spectrum (study 1 , NRS $\geq 6, n=22$; study 2 , NRS $\geq 7, n=17$ ), the TSK (score $\geq 40, n=22$ ), and the FABQ (activity scale $\geq 17$, work scale $\geq 25, n=16$ ). 


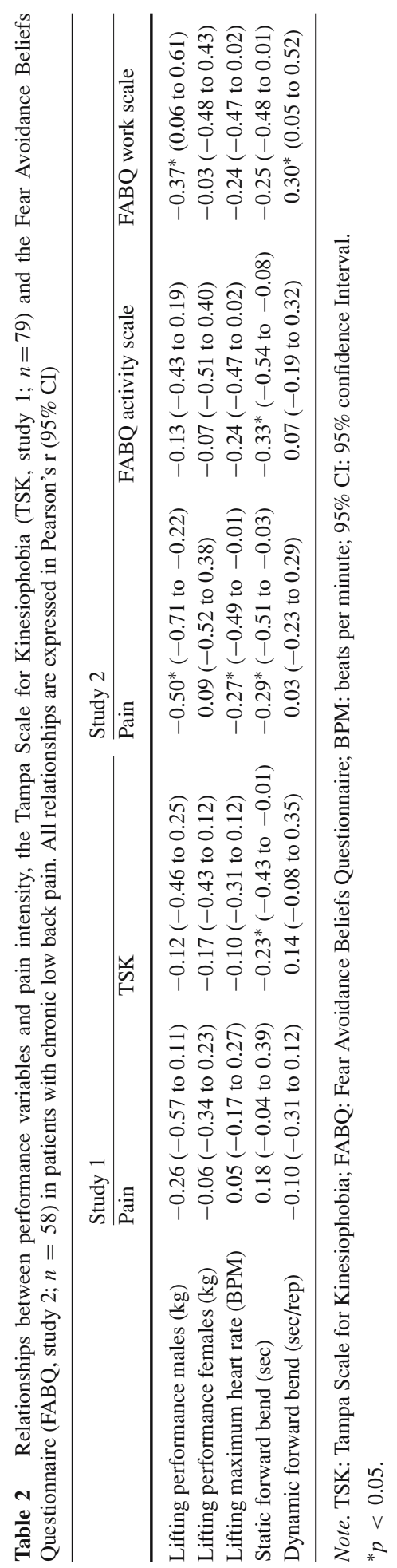

Springer 


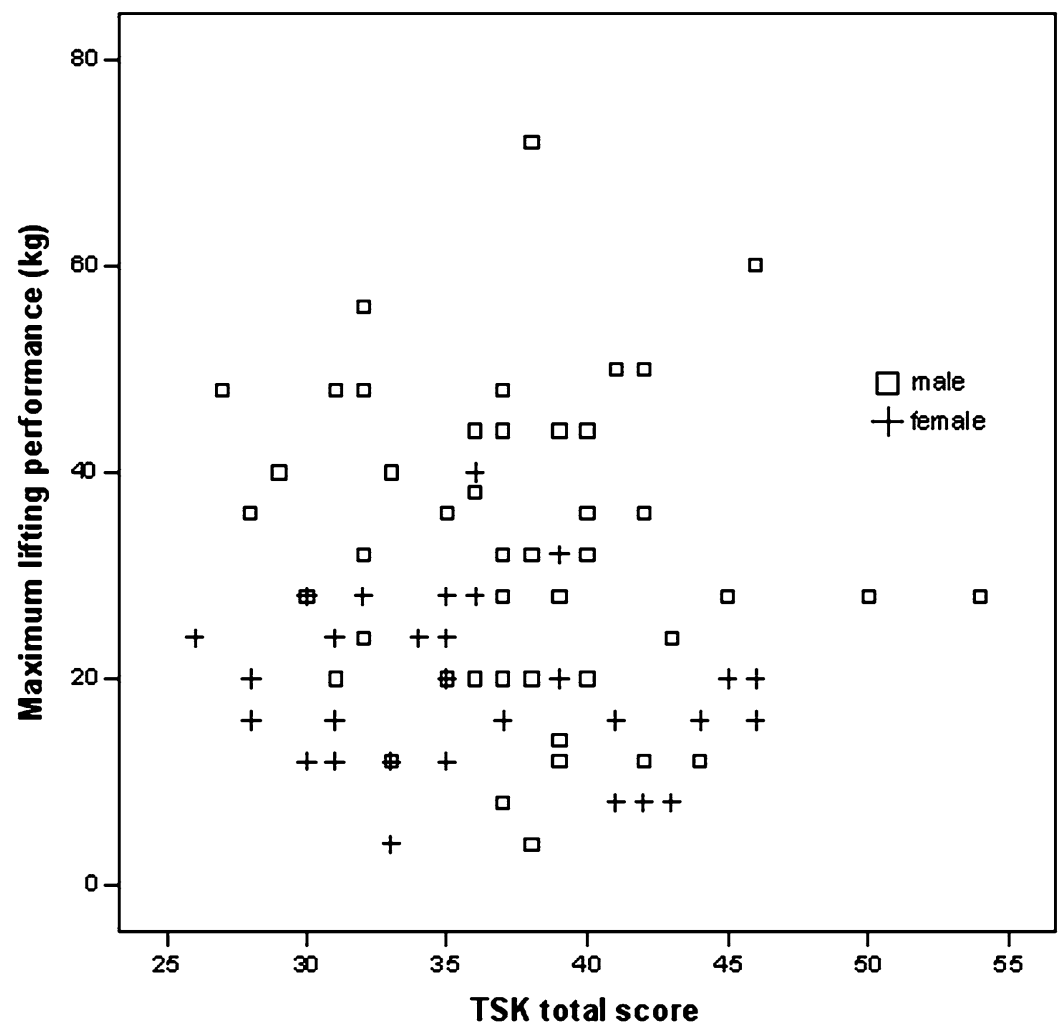

Fig. 1 Plot of maximum lifting performance and scores on the Tampa Scale for Kinesiophobia (TSK) in 79 patients with chronic low back pain

Analyses involving lifting performances were performed for males and females separately. Correlation coefficients between pain intensity or pain related fears and performance variables ranged between $r=0.00$ and $r=0.23$ in study 1 , and between $r=0.00$ and $r=0.26$ in study 2. All correlations were non-significant. Scatter plots of the distribution of pain intensity or pain related fears and performance variables were created to visually analyze patterns in the datasets. As an example, the distribution of pain related fear (TSK) and lifting performances is presented in Fig. 1. Other distributions between pain intensity or pain related fears (TSK or FABQ) and performance variables were similar, but they are not presented.

Results of the multivariate regression analyses are presented in Table 3. Study 1: Gender was the only variable that independently contributed significantly to the regression equation to predict lifting performance. The explained variance was $28 \%$. Both models to predict the other two outcome variables, static forward bend and dynamic forward bend, were non-significant. Study 2: Gender and pain intensity (to a lesser extend) contributed significantly to the regression equation to predict lifting performances. The explained variance was $37 \%$. In the regression analysis to predict static forward bend performances, none of the independent variables contributed significantly to the regression equation (explained variance 27\%). In the regression analysis to predict dynamic forward bending performances none of the independent variables contributed significantly to the regression equation. Collinearity diagnostics were performed for the independent variables. In both studies the average variance inflating factors (VIF) were 
Table 3 Multivariate linear regression models predicting variance in performance in patients with chronic low back pain

\begin{tabular}{|c|c|c|c|c|c|}
\hline & $\beta(95 \% \mathrm{CI})$ & Beta & $p$ & $r^{2}$ change & Model $r^{2}$ \\
\hline \multicolumn{6}{|l|}{ Study $1(n=79)$} \\
\hline \multicolumn{6}{|l|}{ Dependent variable: lifting } \\
\hline$\bullet$ Gender $($ female $=0$, male $=1$ ) & $14.45(7.36$ to 21.54$)$ & 0.48 & $<0.001$ & 0.23 & 0.28 \\
\hline - Constant & $17.01(-9.60$ to 43.62$)$ & - & 0.205 & - & \\
\hline \multirow{2}{*}{\multicolumn{6}{|c|}{$\begin{array}{l}\text { Dependent variable: static forward } \\
\text { bend }\end{array}$}} \\
\hline & & & & & \\
\hline \multicolumn{6}{|l|}{$\bullet$ Model $r^{2}=0.11 ;$ None of the } \\
\hline \multicolumn{6}{|l|}{ independent variables contributed } \\
\hline \multicolumn{6}{|l|}{ significantly to the regression equation } \\
\hline \multirow{2}{*}{\multicolumn{6}{|c|}{$\begin{array}{l}\text { Dependent variable: dynamic forward } \\
\text { bend }\end{array}$}} \\
\hline & & & & & \\
\hline \multicolumn{6}{|l|}{$\bullet$ Model $r^{2}=0.12 ;$ None of the } \\
\hline \multicolumn{6}{|l|}{ independent variables contributed } \\
\hline \multicolumn{6}{|l|}{ significantly to the regression equation } \\
\hline \multicolumn{6}{|l|}{ Study $2(n=58)$} \\
\hline \multicolumn{6}{|l|}{ Dependent variable: lifting } \\
\hline$\bullet$ Gender $($ female $=0$, male $=1$ ) & $14.94(6.15$ to 23.73$)$ & 0.48 & 0.001 & 0.23 & 0.37 \\
\hline - Pain intensity & $-1.83(-3.65$ to -0.01$)$ & -0.29 & 0.049 & 0.08 & \\
\hline - Constant (kg) & $45.70(25.67$ to 65.73$)$ & - & $<0.001$ & - & \\
\hline \multicolumn{6}{|l|}{$\begin{array}{l}\text { Dependent variable: static forward } \\
\text { bend }\end{array}$} \\
\hline • Constant (sec) & $549.15(336.09$ to 762.21$)$ & - & $<0.001$ & - & 0.27 \\
\hline \multicolumn{6}{|l|}{ - None of the other independent } \\
\hline \multicolumn{6}{|l|}{$\begin{array}{l}\text { variables contributed significantly to } \\
\text { the regression equation }\end{array}$} \\
\hline \multirow{2}{*}{\multicolumn{6}{|c|}{ Dependent variable: dynamic forward }} \\
\hline & & & & & \\
\hline \multicolumn{6}{|l|}{$\bullet$ Model $r^{2}=0.18 ;$ None of the } \\
\hline independent variables contributed & & & & & \\
\hline significantly to the regression equation & & & & & \\
\hline
\end{tabular}

greater than 1, and none of the VIF-values were greater than 10. Specifically, the relationship between pain intensity and measures of pain related fear were analyzed. In study 1 , the strength of the relation between pain and the TSK was $r=-0.04$ (ns). In study 2, the strength of the relation between pain intensity and FABQ activity scale was $r=0.07$ (ns), and between pain intensity and FABQ work scale was $r=0.20$ (ns).

\section{Discussion}

This study has demonstrated that the associations between pain intensity and pain related fears on the one hand and FCE performances on the other hand were generally weak or non-significant. Correlations between pain intensity and pain related fears and performances were significant in only 7 out of 25 analyses (Table 2). The strength of these significant relationships ranged from $r=-0.23$ to $r=-0.50$, explaining 5 to $25 \%$ of the variance $\left(r^{2}\right)$. Multivariate regression analyses were non-significant in 3 out of 6 instances. When significant, pain intensity or pain related fear contributed little if any to these models. Relationships are consistent throughout Springer 
the intensity spectra (upper quarter analyses and Fig. 1). Thus, overseeing all the results of this study, it appears that the relationships between pain and pain related fear and performances in an FCE are generally weak or non-existent. Although we realize that interpretations of these results are open for discussion, we interpret the magnitude of the relationships between pain and pain related fears on the one hand and performances in an FCE on the other hand of limited clinical relevance. In comparison to our previous study [12], we have now used two new cohorts, two questionnaires instead of one to measure a wider range of pain related fears, and three performance tests instead of one to measure a wider range of avoidance behaviors. Additionally, we have added heart rate and observations as indices for effort level in lifting. Both pain intensity and pain related fear were poorly associated with indices for effort, explaining 7\% or less of the variance. The results of the 2 new studies presented here are generally consistent with our previous study, which adds to the robustness of the results.

There may be several explanations for the weakness or non-existence of the associations between pain intensity and pain related fears on the one hand, and avoidance behaviors on the other hand. Pain intensity and pain related fears might have been inappropriately operationally defined by the NRS, the TSK and the FABQ, avoidance behavior might have been inappropriately operationally defined by the three performance measures, our study samples differ from samples reported elsewhere, or the variables were appropriately operationally defined, but the relationship was mediated by one or more currently unknown variables. Additionally, a combination of the above may explain our findings.

The NRS, TSK and the FABQ may be considered among the standards to measure pain intensity and pain related fears. The reliability and the validity of the measures for avoidance behavior and pain related fears have been established. Both the performance measure 'heavy lifting' and a postural tolerance test have been used previously in different studies as measures for avoidance behavior $[8,9,12]$. The activities selected are potentially harmful for patients with CLBP [20]. Thus, it seems unlikely that the operational definitions were inappropriate for the constructs measured. Both our study samples are similar to samples reported in other studies reporting on patients with CLBP concerning age, pain intensity, self-reported disability, and amount of fear avoidance beliefs $[8,10]$. This similarity may rule out the plausibility the results of our study are caused by the selection of study samples. While the TSK and the FABQ may be considered among the consented standards to measure pain related fears, it may be possible that the domain measured might be too large and general to be of value in predicting specific behaviors such as the ones used in this study. This in itself could explain the findings of this study and the lack of consistent findings in previous research. However, if the measures are considered valid representations of the constructs pain intensity, pain related fear, and avoidance behavior, then a different explanation should be considered for our findings.

Other variables may serve as a mediator between pain variables and avoidance behavior. As suggested in recent pain literature, two variables should be considered as mediators or confounders: motivation [29] and acceptance [30]. Within the motivational models [29, 31, 32], it is suggested that the value of the goal and the patient's belief in his ability (self-efficacy) to attain this goal is predictive for his behavior. When applied to the results of this study, patients were apparently willing to perform the tests regardless of their pain related fears. They were willing to perform, because they may have been convinced that this would have helped them to reach a valued goal (for example return to work). Contrarily, patients without pain related fears may perform poorly on the tests, because they do not see it to be of any value. Alternatively, a poor performance could be explained if the patient's goal would be to use the test results for financial gain (disability allowance) [33]. In that case, pain related fears would be of little importance to determine a patient's behavior. Within the acceptance model [30], it is suggested that patients may be able to accept their pain or fears as an inevitable part of their lives. Patients 
would report pain or have cognitions such as pain related fears, but are able to function normally with their pain or fears. Some empirical evidence is found to support the applicability of this model within chronic pain [34,35]. If a mediating effect or confounding of one or more different variables is present, then poor or non-existent associations between pain intensity, pain related fears and test performance are very well imaginable. Future studies should be conducted to find empirical evidence for the proposition that constructs as motivation and acceptance are more important predictors for functional capacity than pain or pain related fears. Additionally, other currently unknown variables may have played a mediating role in the relationship between pain variables and avoidance behaviors.

Both self-report and performance measures assess effort-related performance [36]. As such, they cannot be defined independently of the person's behavior. Pain-related disability is a matter of human performance, whether it is observed/measured or reported [36] and this may also apply to patient's behavior in an admission phase of a rehabilitation program. In this stage patients need not only reveal their cognitions and perception of disability, but at the same time present an image to the practitioner [37], to justify the need for treatment [38,39] and perhaps to justify the fact that they are off work due to CLBP. The scores on the questionnaires may thus be an overrating of the 'real' pain or pain related fears. An FCE is a measure of demonstrated ability. Pain behaviors may prevent the patients to perform to their maximal physical capacity. The ratings of effort level indicate a sub maximal performance, suggesting that this behavior has occurred in study 2 (and probably also in study 1, but data were unavailable). Without these pain behaviors, the FCE results might have been higher. On average, the performance-based scores presented in this study may be considered an underrating of the physical abilities of the patients. Consequently, clinical interpretation of the outcomes of effort related assessments should be made with care. We propose that the scores on the questionnaires are interpreted as 'the patient reports that ... (he is fearful), instead of 'the patient is/feels/perceives ... (fearful/fear). For the FCE, we propose that the scores are interpreted as the patient's performance, instead of the patient's capacity (FPE: Functional Performance Evaluation). The performance of a patient depends on his capacity and his willingness to produce [25]. The current study and our previous study show that report of pain and pain related fears explain little of the patient's performances during FCE. Statements that 'a valid assessment of functional capacity cannot be carried out without controlling for fear avoidance beliefs [8] and "pain related fear is more disabling than pain itself' 10 are not supported by the results of this study. The results of this study may not be generalizable to other FCEs or other groups of patients. From the results of the current study it should be concluded that future research aimed at unrevealing 'determinants of performance' in chronic pain should not be restricted to pain and pain related fears only, but include other avenues such as self efficacy [40,41], motivation and acceptance as well.

Acknowledgments The data of study 1 were collected as part of the low back pain disability (LOBADIS) research program, supported by Zorgonderzoek Nederland (ZON) grant number 96-06-006.

\section{References}

1. Innes E, Straker L. Validity of work-related assessments. Work 1999;13:125-52.

2. Innes E, Straker L. Reliability of work-related assessments. Work 1999;13:107-24

3. King PM, Tuckwell N, Barrett TE. A critical review of functional capacity evaluations. Phys Ther 1998;78:85266.

4. Waddell G, Burton AK. Concepts of rehabilitation for the management of low back pain. Best Pract Res Clin Rheumatol 2005;19:655-70.

5. Vlaeyen JW, Linton SJ. Fear-avoidance and its consequences in chronic musculoskeletal pain: a state of the art. Pain 2000;85:317-32. 
6. Gross DP. Are functional capacity evaluations affected by the patient's pain? Curr Pain Headache Rep 2006;10:107-13.

7. Kori SH, Miller RP, Todd DD. Kinesiophobia: a new view of chronic pain behavior. Pain Manage 1990;35-43.

8. Vlaeyen JW, Kole-Snijders AM, Boeren RG, van Eek H. Fear of movement/(re)injury in chronic low back pain and its relation to behavioral performance. Pain 1995;62:363-72.

9. Geisser ME, Robinson ME, Miller QL, Bade SM. Psychosocial factors and functional capacity evaluation among persons with chronic pain. J Occup Rehabil 2003;13:259-76.

10. Crombez G, Vlaeyen JW, Heuts PH, Lysens R. Pain-related fear is more disabling than pain itself: evidence on the role of pain-related fear in chronic back pain disability. Pain 1999;80:329-39.

11. Verbunt JA, Westerterp KR, van der Heijden GJ, Seelen HA, Vlaeyen JW, Knottnerus JA. Physical activity in daily life in patients with chronic low back pain. Arch Phys Med Rehabil 2001;82:726-30.

12. Reneman MF, Jorritsma W, Dijkstra SJ, Dijkstra PU. Relationship between kinesiophobia and performance in a functional capacity evaluation. J Occup Rehabil 2003;13:277-85.

13. Kuijer W, Brouwer S, Preuper HR, Groothoff JW, Geertzen JH, Dijkstra PU. Work status and chronic low back pain: exploring the international classification of functioning, disability and health. Disabil Rehabil 2006;28:379-88.

14. Roland M, Morris R. A study of the natural history of back pain. Part I: development of a reliable and sensitive measure of disability in low-back pain. Spine 1983;8:141-4.

15. Waddell G, Newton M, Henderson I, Somerville D, Main CJ. A Fear-Avoidance Beliefs Questionnaire (FABQ) and the role of fear-avoidance beliefs in chronic low back pain and disability. Pain 1993;52:15768.

16. Brouwer S, Kuijer W, Dijkstra PU, Goeken LN, Groothoff JW, Geertzen JH. Reliability and stability of the Roland Morris Disability Questionnaire: intra class correlation and limits of agreement. Disabil Rehabil 2004;26:162-5.

17. Swinkels-Meewisse EJ, Swinkels RA, Verbeek AL, Vlaeyen JW, Oostendorp RA. Psychometric properties of the Tampa Scale for kinesiophobia and the fear-avoidance beliefs questionnaire in acute low back pain. Man Ther 2003;8:29-36.

18. Functional Capacity Evaluation Manual. One ed. Duluth, MN, USA: Isernhagen Work Systems, 1997.

19. Fishbain DA, Cutler RB, Rosomoff H, Khalil T, Abdel-Moty E, Steele-Rosomoff R. Validity of the dictionary of occupational titles residual functional capacity battery. Clin J Pain 1999;15:102-10.

20. Lotters F, Burdorf A, Kuiper J, Miedema H. Model for the work-relatedness of low-back pain. Scand J Work Environ Health 2003;29:431-40.

21. Straker LM. A review of research on techniques for lifting low-lying objects: 2. Evidence for a correct technique. Work 2003;20:83-96.

22. Brouwer S, Reneman MF, Dijkstra PU, Groothoff JW, Schellekens JM, Goeken LN. Test-retest reliability of the Isernhagen Work Systems Functional Capacity Evaluation in patients with chronic low back pain. J Occup Rehabil 2003;13:207-18.

23. Gross DP, Battie MC. Reliability of safe maximum lifting determinations of a functional capacity evaluation. Phys Ther 2002;82:364-71.

24. Reneman MF, Dijkstra PU, Westmaas M, Goeken LN. Test-retest reliability of lifting and carrying in a 2-day functional capacity evaluation. J Occup Rehabil 2002;12:269-75.

25. Reneman MF, Fokkens AS, Dijkstra PU, Geertzen JH, Groothoff JW. Testing lifting capacity: validity of determining effort level by means of observation. Spine 2005;30:E40-E46.

26. Reneman MF, Jorritsma W, Schellekens JM, Goeken LN. Concurrent validity of questionnaire and performance-based disability measurements in patients with chronic nonspecific low back pain. J Occup Rehabil 2002;12:119-29.

27. Gross DP, Battie MC. Construct validity of a kinesiophysical functional capacity evaluation administered within a worker's compensation environment. J Occup Rehabil 2003;13:287-95.

28. Munro BH, Visintainer MA, Batten Page E. Statistical methods for health care research. Philadelphia: JB Lippencott Company, 1986.

29. Jensen MP, Nielson WR, Kerns RD. Toward the development of a motivational model of pain self-management. J Pain 2003;4:477-92.

30. Hayes SC, Luoma JB, Bond FW, Masuda A, Lillis J. Acceptance and commitment therapy: model, processes and outcomes. Behav Res Ther 2006;44:1-25.

31. McCracken LM, Eccleston C. Coping or acceptance: what to do about chronic pain? Pain 2003;105:197-204.

32. Viane I, Crombez G, Eccleston C et al. Acceptance of pain is an independent predictor of mental well-being in patients with chronic pain: empirical evidence and reappraisal. Pain 2003;106:65-72.

33. Reneman MF, Kool J, Oesch P, Geertzen JH, Battie MC, Gross DP. Material handling performance of patients with chronic low back pain during Functional Capacity Evaluation; A comparison between three countries. Disabil Rehabil 2006. 
34. McCracken LM, Vowles KE, Eccleston C. Acceptance-based treatment for persons with complex, long standing chronic pain: a preliminary analysis of treatment outcome in comparison to a waiting phase. Behav Res Ther 2005;43:1335-46.

35. Dahl J, Wilson KG, Nilsson A. Acceptance and commitment therapy and the treatment of persons at risk for long-term disability resulting from stress and pain symptoms: a preliminary randomized trial. Behav Ther 2004;35:785-801.

36. Fordyce WE. Back pain in the workplace. Management of disability in nonspecific conditions. A report of the task force of the International Society of the Study of Pain. Seattle, WA, USA: IASP Press, 1995.

37. Simmons M. Physical function and physical performance in patients with pain: what are the measures and what do they mean. Refresher courses on pain management held in conjuction with the 9th world congress on pain. Vienna, Austria: IASP, 1999.

38. Watson PJ. Non-physiological determinants of physical performance in musculoskeletal pain. Refresher courses on pain management held in conjuction with the 9th world congress on pain. Vienna, Austria: IASP, 1999.

39. Hadler NM. If you have to prove you are ill, you can't get well. The object lesson of fibromyalgia. Spine 1996;21:2397-400.

40. Feuerstein M, Beattie P. Biobehavioral factors affecting pain and disability in low back pain: mechanisms and assessment. Phys Ther 1995;75:267-80.

41. Lacker JM, Carosella AM, Feuerstein M. Pain expectancies, pain, and functional self-efficacy expectancies as determinants of disability in patients with chronic low back disorders. J Consult Clin Psychol 1996;64:21220. 